\title{
Plantas comercializadas como medicinais no Município de Barra do Piraí, RJ
}

\author{
Cláudio Ernesto Taveira Parente ${ }^{1}$ \\ Maria Mercedes Teixeira da Rosa ${ }^{2}$
}

\begin{abstract}
RESUMO
O município de Barra do Piraí localiza-se na região média do rio Paraíba do Sul e engloba áreas de Floresta Atlântica de encosta em diferentes estágios sucessionais. Os dados foram obtidos através de entrevistas semi-estruturadas a dois informantes (erveiros) que comercializam plantas medicinais na única feira-livre da cidade, bem como pela aplicação de questionários com perguntas diretas e fechadas a 100 consumidores dessas plantas. Visitaram-se quatro sítios de coleta e/ou cultivo onde foram coletadas 100 espécies pertencentes a 42 famílias botânicas. Elaborou-se uma tabela organizada em ordem alfabética de família acompanhada pelo nome científico, nome vulgar e dados fornecidos pelos informantes. Dentre as espécies coletadas, cerca de $25 \%$ foram obtidas em áreas florestadas, evidenciando-se o importante papel dos erveiros na coleta e fornecimento de plantas medicinais da Floresta Atlântica.
\end{abstract}

Palavras-chaves: Etnobotânica, plantas medicinais, Floresta Atlântica.

\begin{abstract}
The municipal district of Barra do Piraí is located in the medium region of Paraíba do Sul river, and includes Atlantic low mountain rain forest areas in different succession levels. Data was obtained through semi-structured interviews made with two informants ("erveiros" - people that harvest and eventually sell medicinal plants). In this case, the market was the city's single fair. Questionnaires with straight and close-ended questions were also used for a hundred consumers of these plants. A hundred species from 42 botanical botanical families were gathered at the four visited harvest and/ or plantation farms. A table was organized by family alphabet order including scientific and popular names, and also data reported by the informants. Among the gathered species, $25 \%$ were obtained from forest areas, showing the "erveiros" important role at the Atlantic forest medicinal plants harvesting and supply.
\end{abstract}

Keywords: Ethnobotany, medicinal plants, Atlantic rain forest.

\section{INTRODUÇÃO}

As florestas tropicais em todo o mundo vêm sofrendo o impacto do crescimento populacional e de processos de exploração inadequada, levando a redução das áreas florestadas (Peixoto et al., 1995). A floresta da costa atlântica brasileira, embora ocorra, em grande parte, próxima a grandes centros urbanos e acessível a importantes instituições científicas carece ainda de estudos botânicos em seus mais diferentes aspectos (Peixoto et al., 1995.).

A região sob influência do rio Paraíba do Sul, onde está situado o município de Barra do Piraí, no estado do Rio de Janeiro, era coberta pela Floresta Atlântica. Constituída em sua maior parte por mata de encosta, esta teve sua exploração iniciada no século passado com a retirada de madeiras consideradas nobres. Posteriormente o cultivo de café em grandes

\footnotetext{
${ }^{1}$ Bolsista de Iniciação Científica PIBIC/CNPq - Depto. de Botânica - Universidade Federal Rural do Rio de Janeiro ${ }^{2}$ Professora Adjunto - Depto de Botânica - Universidade Federal Rural do Rio de Janeiro, Seropédica, RJ. CEP: 23851970. email: mercedes@ufrrj.br
} 
extensões, de outras culturas como o milho e a cana-de-açúcar em menor escala e também a pecuária, levaram à descaracterização da maior parte de sua cobertura vegetal.

A etnobotânica, ciência que estuda as interações entre populações humanas e plantas (Martin, 1995), assim como investiga novos recursos vegetais, tem merecido algum destaque na atualidade, devido ao crescente interesse pelos produtos naturais. No entanto a desagregação dos sistemas de vida tradicionais que acompanha a devastação do ambiente e a intrusão de novos elementos culturais, ameaça muito de perto um acervo de conhecimentos empíricos e um patrimônio genético de valor inestimável para as gerações futuras (Amorozo \& Gély, 1988).

Aplica-se o termo conhecimento tradicional para referir-se ao conhecimento que o povo local, isto é, residentes da região sob estudo, conhece sobre o ambiente natural (Martin, 1995).

Toda sociedade humana acumula um acervo de informações sobre o ambiente que a cerca, que vai lhe possibilitar interagir com ele para prover suas necessidades de sobrevivência. Neste acervo, inscreve-se o conhecimento relativo ao mundo vegetal com o qual estas sociedades estão em contato (Amorozo, 1996).

Desta forma estudos relacionados com a medicina popular têm merecido cada vez maior atenção devido a gama de informações e esclarecimentos que fornecem à ciência contemporânea. É notável o crescente número de pessoas interessadas no conhecimento de plantas medicinais, inclusive pela consciência dos males causados pelo excesso de quimioterápicos causados no combate as doenças. Remédios à base de ervas que se destinam a doenças pouco entendidas pela medicina moderna - tais como: câncer, viroses, doenças que comprometam o sistema imunológico, entre outras - tornaram-se atrativos para o consumidor (Sheldon et al., 1997). Um outro fator de destaque na crescente procura da fitoterapia, é a vigente carência de recursos dos órgãos públicos de saúde e os incessantes aumentos de preços dos medicamentos industrializados. No entanto, pela facilidade de obtenção e despreparo de quem as utiliza são também observados casos de intoxicação de plantas tidas como medicinais.

Ao se estudar o complexo medicina folclórica ou popular, deve-se enfatizar a necessidade de se estudar simultaneamente a pessoa que possui os conhecimentos, bem como o ambiente em que essas práticas são espontaneamente aceitas. De mesma importância, a sistematização desse estudo deve considerar, em primeira instância, o fato cultural em sí, como a nosografia, etiologia, diagnóstico, terapêutica, farmacopéia disponível, profilaxia e higiene destas práticas, e, em segundo lugar, estudar o indivíduo que ministra a cura ou que tem o poder de curar, como o rezador, o benzedor, o raizeiro, o curandeiro e outros (Savastano \& Di Stasi, 1996).

Segundo Martin (1995) nenhuma pesquisa econômica de recursos biológicos está completa sem um detalhado estudo de plantas e animais vendidos em mercados locais. Muitas plantas medicinais, ornamentais e outros produtos tem um valor estritamente regional que somente podem ser descobertos pela conversação com produtores, vendedores e consumidores.

Vale ressaltar ainda que a exploração de espécies medicinais com potencial de utilização pelo homem tem levado a reduções drásticas em suas populações naturais, especialmente pelo desconhecimento dos mecanismos de perpetuação delas na floresta. Assim, a identificação e o estudo das espécies medicinais trarão subsídios para a sua exploração sustentável em seu ecossistema (Reis, 1996).

Este trabalho adquire portanto, importância fundamental em vista do caráter dinâmico da medicina popular e do desaparecimento de espécies vegetais decorrente da histórica devastação das florestas 
tropicais, bem como das práticas culturais das populações. Dentro deste quadro é portanto necessário registrar, o quanto antes, todas as informações possíveis sobre o emprego de plantas medicinais.

\section{MATERIAL E MÉTODOS}

\section{I. Área de estudo}

O trabalho foi desenvolvido no município de Barra do Piraí, Rio de Janeiro, na região de confluência dos rio Piraí e Paraíba do Sul. Nesta região o clima é sub-quente úmido com pluviosidade em torno de $1.500 \mathrm{~mm}$ anuais, atingindo a máxima no verão, com inverno quase seco. Apresenta topografia acidentada caracterizada pela predominância de morros de contorno hemisférico constituindo, devido a extensão e quantidade, o chamado "mares de morros" (Rizzini,1976).

De acordo com Sydenstricker (1993) a população do município de Barra do Piraí é de cerca de 78.437 habitantes, sendo a taxa de alfabetização de $85 \%$ da população. As principais atividades econômicas relacionamse ao comércio, indústria e pecuária.

Com o declínio da cultura do café na região, muitas fazendas foram abandonadas, havendo então uma expansão da área coberta por florestas secundárias. A partir da década de quarenta, devido a construção da Represa de Ribeirão das Lajes, a área teve sua preservação garantida pela LIGHT/CEDAE como floresta protetora de manancial hídrico, passando a ser regida por leis federal e estadual (Peixoto et al., 1995). Esta mesma área segundo os mesmos autores, pode ser caracterizada na atualidade por três fitofisionomias distintas: 1) vegetação graminóide rala ou mais ou menos densa cobrindo morrotes que tomam a aparência de morros desnudos; 2) vegetação graminóide com árvores pioneiras em povoamentos densos ou ralos; 3) vegetação arbórea secundária em diferentes estados serais.

\section{Trabalho de campo e de laboratório}

A coleta de dados foi feita a partir de duas fontes: os erveiros que comercializam plantas medicinais na feira-livre de Barra do Piraí e os usuais consumidores destas plantas.

Inicialmente procederam-se visitas à feira-livre a fim de estabelecer contato com os erveiros e consumidores. Esta feira, que é a única na cidade, funciona na Travessa Assunção às quintas-feiras e aos domingos, sendo este último o dia de maior movimento. Nesta feira são encontradas principalmente barracas com produtos hortifrutigranjeiros e somente quatro com plantas medicinais.

Após conversas informais, onde foram explanadas claramente as intenções e metas do projeto (Alexiades, 1996), foram marcadas saídas a campo nos sítios de cultivo e/ou coleta dos erveiros que mais se identificaram com nossa proposta de trabalho.

Com os erveiros adotou-se a metodologia de entrevistas semi-estruturadas aplicadas nas visitas à feira e nas saídas ao campo (Martin, 1995), enquanto que para os consumidores elaborou-se um questionário com questões fechadas e diretas sobre procedência, frequiência e métodos de utilização de plantas medicinais (Alexiades, 1996).

Nos sítios de coleta e/ou cultivo dos erveiros foram coletadas as espécies comercializadas, com anotação das observações de campo e dados referentes à nomenclatura vulgar, indicação terapêutica, modo de preparo, dosagem, parte utilizada, etc.

$\mathrm{Na}$ padronização das indicações terapêuticas procurou-se seguir as propostas por Debuigne (1974), dentro do possível.

O material botânico coletado foi herborizado segundo métodos habituais em Botânica, sendo as exsicatas posteriormente incluídas no acervo do herbário do Departamento de Botânica da UFRRJ (RBR).

A identificação do material foi feita através de bibliografia especializada, de comparação com exsicatas dos herbários RBR e do Jardim Botânico do Rio de Janeiro (RB), além de consulta a especialistas, quando necessário. 


\section{RESULTADOS}

Foram coletadas 101 espécies de plantas comercializadas como medicinais na feira livre da cidade de Barra do Piraí. Estas espécies pertencem a 42 famílias botânicas, sendo as mais representativas em número de espécies indicadas na Figura 1.

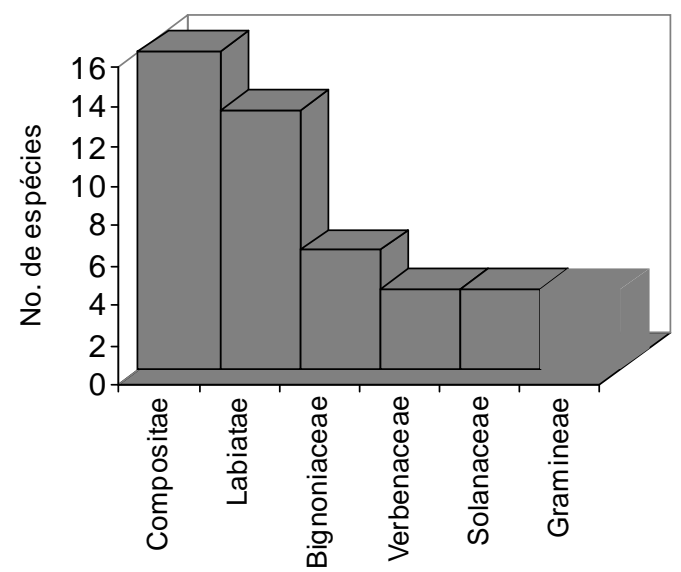

Figura 1 - Famílias mais representativas em número de espécies.

O material botânico coletado encontrase organizado em ordem alfabética de família acompanhada do nome científico e vulgar (Tabela 1).

Foram visitados quatro sítios de cultivo e/ou coleta de dois erveiros, Sra. Maria Aparecida e Sr. Jorge Borges da Paixão, que já trabalhavam com o comércio de plantas medicinais há vários anos e mostraram-se mais acessíveis e interessados em colaborar com esta pesquisa. Dessas áreas, duas são locais de cultivo localizadas próximo de suas residências e as outras duas situadas em áreas de Mata Atlântica de encosta em regeneração, mas com sinais de atividade antrópica. Dentre o total de espécies identificadas encontrou-se uma maior proporção de plantas cultivadas pelos erveiros (44\%), seguida de espécies ruderais $(31 \%)$ e $25 \%$ de espécies extraídas da mata (Fig.2).

Distribuiram-se 100 questionários, visando obter informações, junto aos consumidores, sobre procedência, freqüência e métodos de utilização de plantas medicinais, dos quais foram respondidos 97. Dentre os

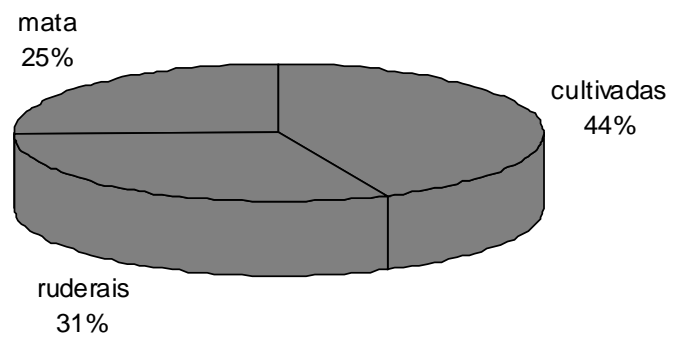

Figura 2 - Locais de coleta das plantas comercializadas como medicinais.

entrevistados havia um total de 26 homens e 74 mulheres. Segundo os dados obtidos no questionário, cerca de $79 \%$ das pessoas que freqüentam a feira livre da cidade costumam pedir informações relacionadas a utilização de plantas medicinais aos erveiros, mostrando que os mesmos têm uma participação ativa no fornecimento de tais plantas. Constatou-se ainda, que os principais motivos para a utilização das espécies medicinais pela população são: preço bem inferior aos medicamentos industrializados e a crença de que são formas mais saudáveis de tratamento.

$\mathrm{Na}$ Tabela 1 encontram-se também organizados os dados relativos à indicação terapêutica acompanhados da forma de utilização, parte utilizada e observações.

Foram listadas 27 indicações terapêuticas, sendo a de cunho ritualístico com maior número de espécies (18), seguida de sintomas gripais (14) e de problemas de pele e cicatrizantes de uma forma geral com 11 espécies (Fig. 3).

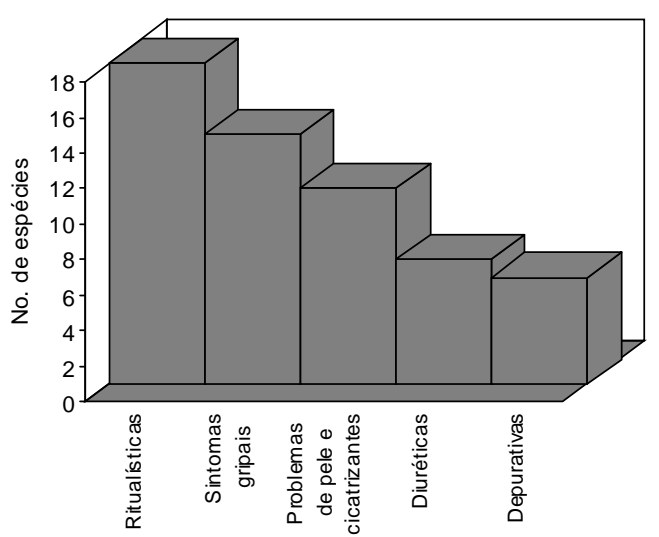

Figura 3 - Indicações terapêuticas mais representativas em número de espécies. 
Plantas comercializadas como medicinais no Município de Barra do Piraí, RJ

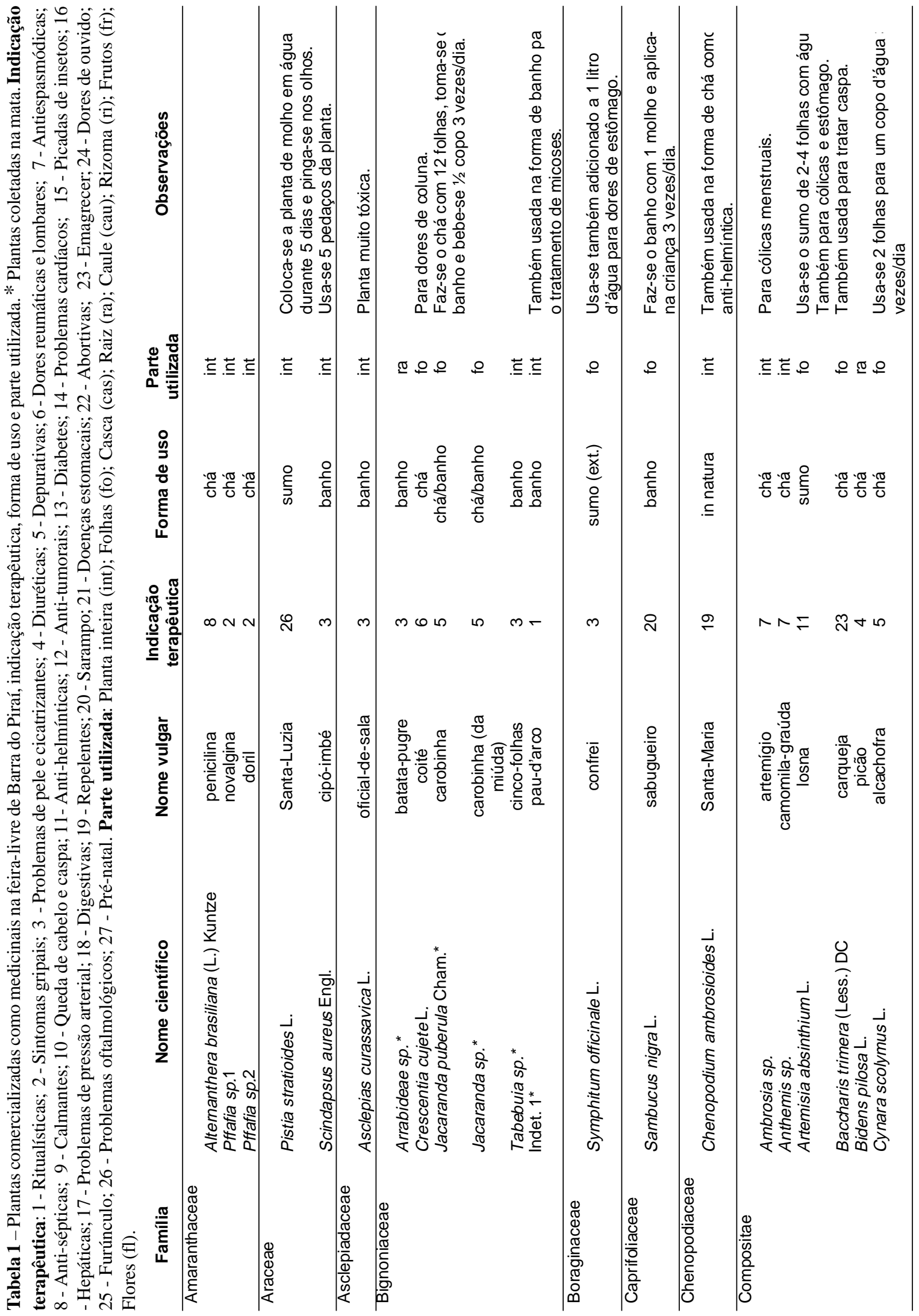

Rodriguésia 52(80): 47-59. 2001. 

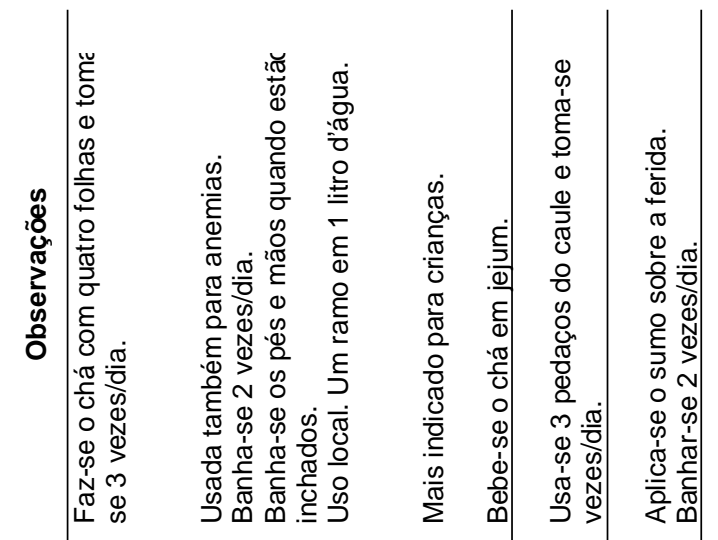

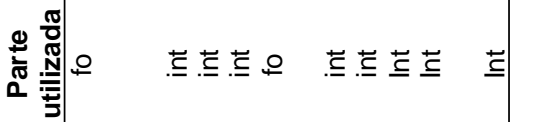

.

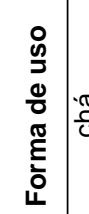

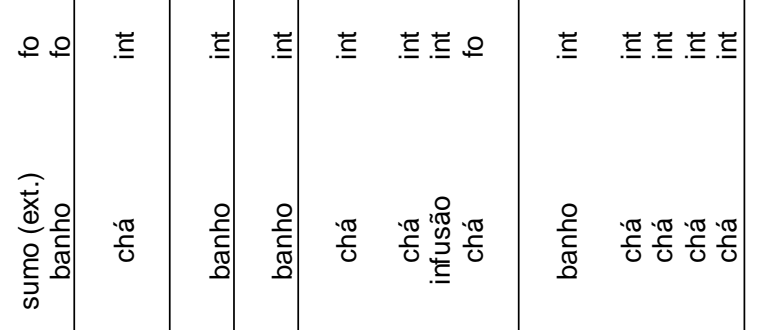

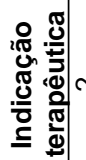

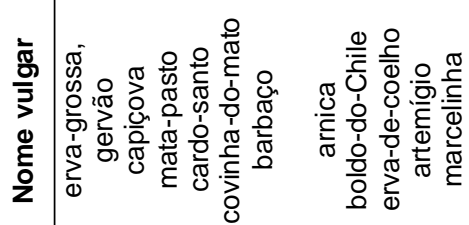
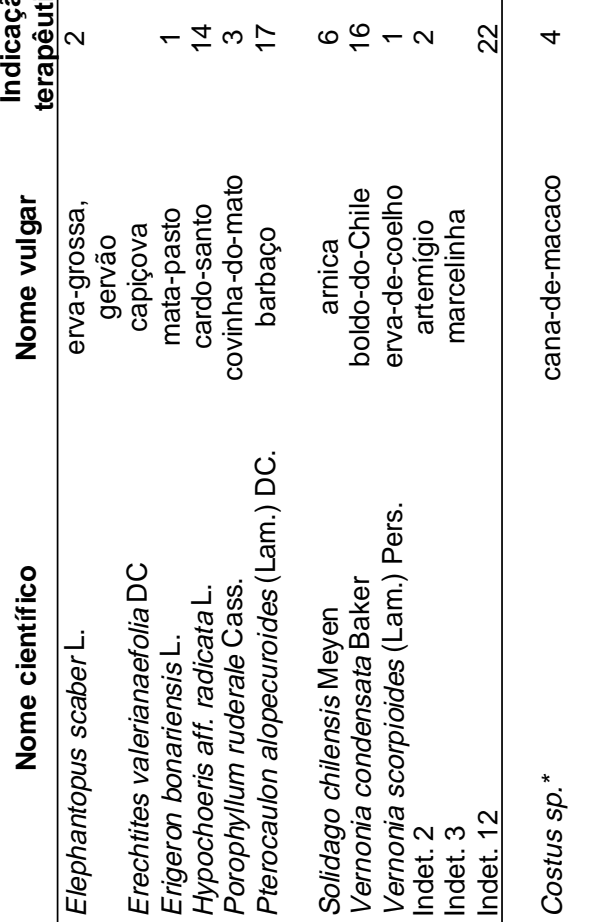

m-

$\wedge$

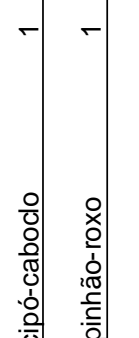

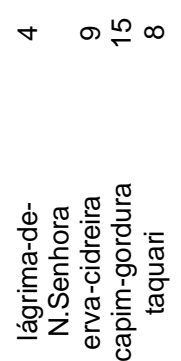

- $\sim \sim \sim \stackrel{\infty}{\sim}$

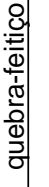

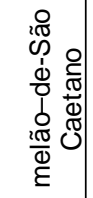

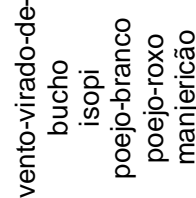

के

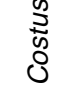

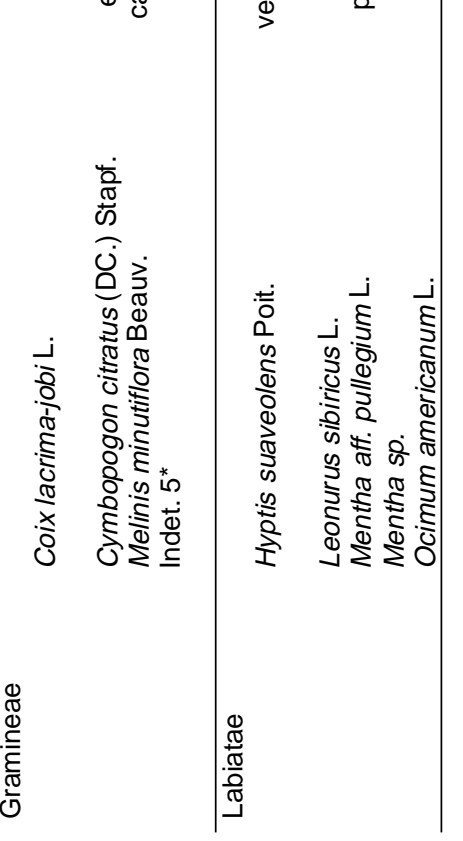

Rodriguésia 52(80): 47-59. 2001. 


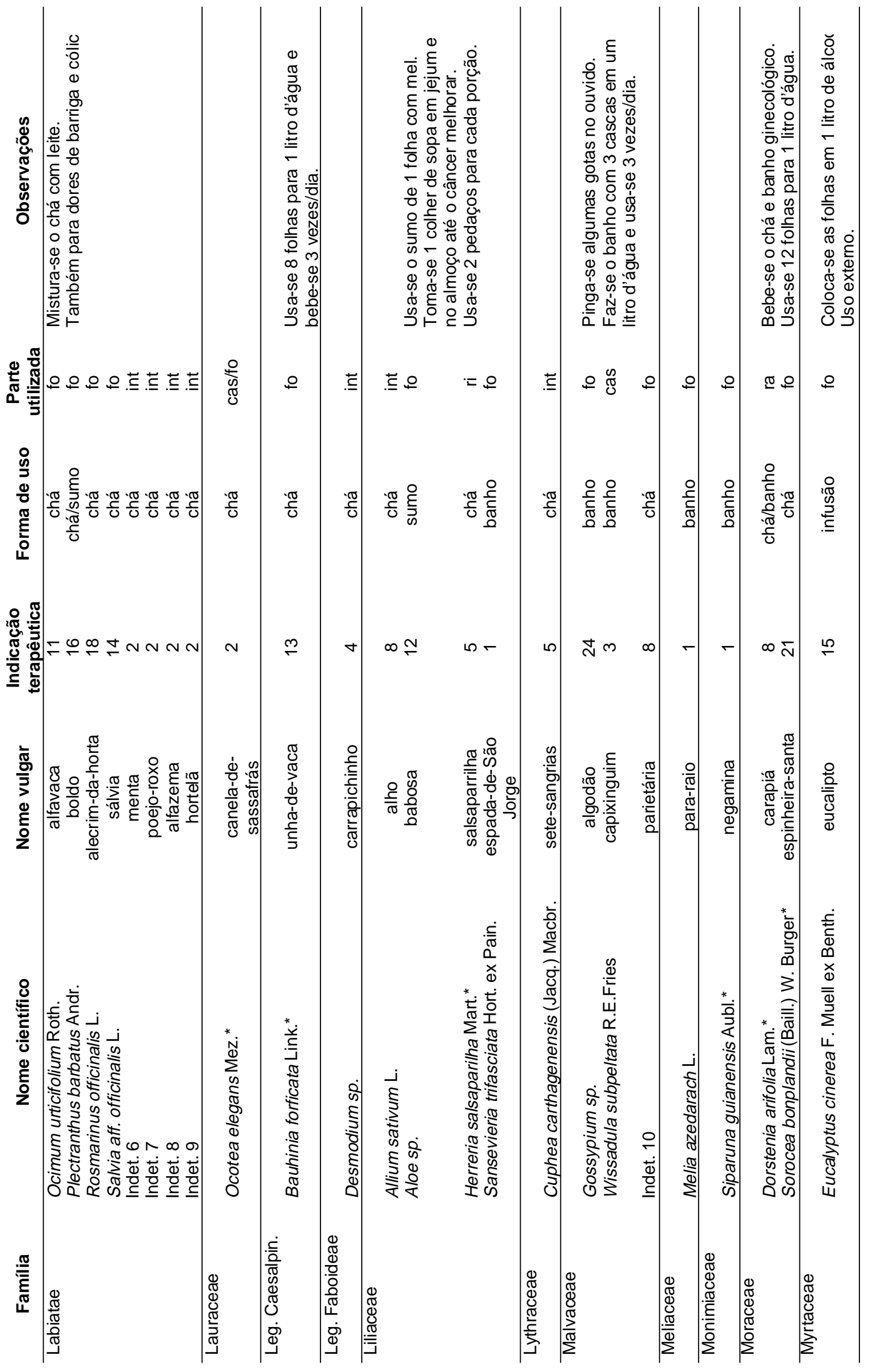

Rodriguésia 52(80): 47-59. 2001. 


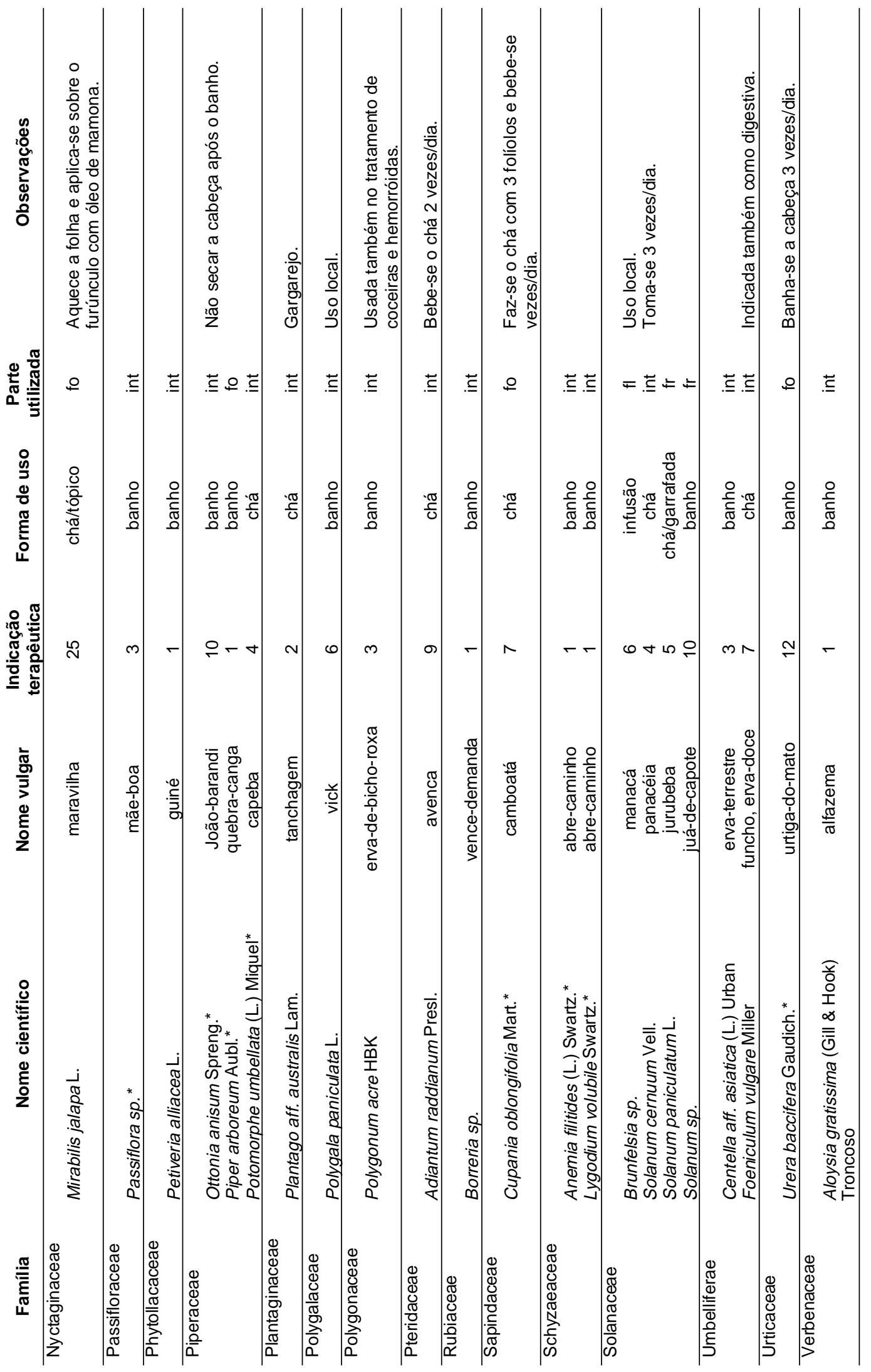

Rodriguésia 52(80): 47-59. 2001. 
Em relação à forma de utilização das plantas, observou-se a predominância dos chás para beber com $51 \%$, banhos com $39 \%$ e outros usos como garrafadas, sumos, infusões e in natura com $10 \%$.

No que se refere a parte utilizada, encontrou-se um amplo uso de toda planta na preparação dos remédios (54\%) seguido por folhas $(34 \%)$ e uma menor porcentagem de raízes, frutos, cascas, flores etc. (12\%).

\section{DISCUSSÃO E CONCLUSÕES}

Embora o contato com os erveiros tenha sido feito em uma única feira, tais informantes atendem a outras localidades do município (p. ex. distrito de Ipiabas) e mesmo em cidades vizinhas (p. ex. município de Piraí, RJ).

De acordo com os dados levantados em relação a forma de coleta das plantas pelos erveiros, observa-se uma evidente predileção pela obtenção de espécies medicinais cultivadas, seguida pelas espécies ruderais e finalmente das extraídas na mata, que contribuem com cerca de $25 \%$ do total de espécies coletadas (Fig. 2). Ressalta-se ainda que a obtenção das plantas ruderais deu-se indistintamente, tanto nos sítios de cultivo quanto nos de coleta na mata.

Em relação ao número de plantas obtidas pelo extrativismo, que se revelou bastante expressivo, Reis (1996) destaca a importância de se estabelecer linhas de ação voltadas para o desenvolvimento de técnicas de manejo sustentado, visando a utilização destas espécies vegetais pelo homem, aliada à manutenção do equilíbrio dos ecossitemas tropicais.

$\mathrm{O}$ mesmo autor sugere ainda que, para o manejo dessas espécies, as estratégias a serem adotadas devem levar em conta, dentre vários aspectos, se o indivíduo inteiro será abatido ou se apenas parte dele será retirada.

Os erveiros têm uma participação ativa no fornecimento de plantas medicinais para a população, praticamente se igualando à aquisição por meio de cultivo em suas próprias residências e doadas por parentes e amigos, fato muito observado em cidades do interior.
No entanto, em trabalho realizado no Rio Grande do Sul, Somavilla \& Canto-Dorow (1996) citam que $76 \%$ das plantas utilizadas como medicinais são obtidas através de amigos e também pelo hábito de cultivo caseiro, encontrando-se uma porcentagem bem menor para as espécies adquiridas com erveiros ou em farmácias.

O número de espécies coletadas referidas na Tabela 1 (101 espécies), praticamente se equipara ao número coletado em um levantamento semelhante realizado na represa de Ribeirão das Lajes, situada no município de Piraí (limítrofe ao de Barra do Piraí), onde foram enumeradas cerca de 109 espécies pertencentes a 52 famílias (Silva et al., 1992). Comparando-se os dados relativos às famílias mais representativas com aqueles encontrados por Silva et al. (op.cit.), observa-se coincidência somente entre as famílias Compositae (3 espécies) e Bignoniaceae (1 espécie).

Roveratti (1998) em sua análise comparativa de espécies medicinais utilizadas em diferentes regiões do Brasil, refere-se a cinco espécies como sendo as de maior frequiência em todos os levantamentos analisados. Dentre estas, Cymbopogon citratus, Artemisia absinthium e Vernonia condensata, foram relatadas como medicinais pelos informantes da região. Este mesmo autor ressalta o regionalismo relacionado à utilização de Chenopodium ambrosioides, citada em $70 \%$ dos levantamentos feitos nas comunidades da região Norte e Nordeste enquanto que nos estados do Sul e Sudeste notou-se ser uma espécie bem pouco utilizada. Fato não observado no presente trabalho, já que os informantes da região cultivam esta mesma espécie e a comercializam na feira livre do município como anti-helmíntica.

De acordo com a Tabela 1, são citadas 27 indicações terapêuticas sendo que algumas agrupam diferentes sintomatologias, como por exemplo, em sintomas gripais incluem-se dor de cabeça, febre, tosse, etc. Já no trabalho de Somavilla \& Canto-Dorow (1996), são 
apresentadas 48 indicações distribuídas em tópicos mais específicos. Estes mesmos autores citam problemas digestivos, gripe e antinflamatórios como as indicações terapêuticas mais representativas, enquanto que o presente trabalho, refere-se a ritualísticas, sintomas gripais e problemas de pele e feridas.

Ressalta-se o grande número de citações de plantas associadas a práticas mágicoreligiosas utilizadas na forma de "banhos de descarrego" (Fig. 3), que segundo Camargo (1988), são destinadas a induzir o bem-estar e de acordo com os informantes têm o poder de afastar maus espíritos, mau olhado, quebranto, etc. Autores como Camargo (op.cit.), Verger (1995) entre outros, desenvolveram trabalhos relacionados a estas formas de utilização, destacando a importância de uma investigação de caráter farmacobotânico destas plantas em função dos princípios ativos, responsáveis pelos efeitos que causam àqueles que delas se utilizam.

Dentre as plantas citadas em trabalhos de Albuquerque \& Chiapetta (1994; 1995 e 1996) sobre a etnobotânica de rituais afrobrasileiros, 17 espécies foram coletadas na área de estudo com diversas indicações terapêuticas. Destas, apenas Hedychium coronarium, Jatropha gossypifolia, Lygodium volubile, Petiveria alliacea e Sansevieria trifasciata foram indicadas como ritualísticas pelos informantes da região (Tabela 1). Embora estas espécies tenham sido relatadas apenas por sua utilização ritualística, várias delas são citadas em bibliografia como tendo propriedades terapêuticas. Segundo Ribeiro \& Gomes (1986) foi verificada a ação anti-hipertensiva e diurética de $H$. coronarium. Já Schvartsman (1979) relata, para J. gossypifolia, a presença de glicosídios que apresentam ação estimulante sobre a musculatura gastrintestinal como sendo esta substância uma das responsáveis pelo seu efeito purgativo. Almeida (1993) ressalta ainda que $P$. alliacea é reconhecida popularmente como uma planta medicinal altamente tóxica, requerendo grandes cuidados quanto a sua ingestão.

$\mathrm{Na}$ preparação dos remédios, encontraram-se resultados semelhantes aos obtidos por Amorozo \& Gély (1988), Rosa et al.(1991) entre outros, onde predominam o uso dos chás para beber. Apesar de em outros trabalhos (Camargo, 1985; Amorozo \& Gély, 1988), as garrafadas serem citadas freqüentemente, no presente estudo, houve apenas uma referência.

Em relação a parte utilizada, observouse a predominância do uso de toda planta, diferentemente dos trabalhos supra citados, onde ocorre uma maior utilização das folhas.

O uso combinado com outras plantas é bastante freqüente, assim como a utilização de outros ingredientes na preparação dos remédios, tais como: leite, mel, vinhos, etc. Simões (1989) previne que esta prática é perigosa, porque nem sempre o processo de preparação mais indicado é o mesmo para plantas diferentes e a combinação pode resultar em efeitos imprevisíveis.

Matos (1989), ressalta ainda os riscos da utilização indiscriminada de plantas medicinais, pois a maioria das plantas utilizadas não estão sujeitas a uma legislação farmacêutica que garanta a qualidade do material. Plantas frescas geralmente são conseguidas em cultivos caseiros e as plantas secas são adquiridas, na maior parte dos casos, em raizeiros que as comercializam em feiras e mercados.

Segundo Matos (op. cit.) dentre os principais riscos no uso de plantas medicinais estão: o uso descuidado de plantas tóxicas, a utilização de plantas que contenham substâncias tóxicas de ação retardada, o uso de plantas mofadas por terem sido mal preparadas e mantidas em recipientes e locais impróprios e o uso de plantas indicadas ou adquiridas erradamente. Nestes casos tanto a conservação e preparo do material, quanto a certeza de que realmente é a espécie correta, só podem ser garantidas com base no 
conhecimento do raizeiro que pode ser um simples vendedor ou um especialista no assunto, cuja formação representa a cultura tradicional passada de geração a geração.

Inúmeras plantas utilizadas na medicina popular apresentam substâncias consideradas tóxicas, portanto estas plantas precisam ser manuseadas e utilizadas com o máximo cuidado. $\mathrm{Na}$ área estudada foram listadas como medicinais, várias espécies consideradas tóxicas:

- Asclepias curassavica (oficial-desala). Matos (1989) relata que esta espécie é portadora de glicosídios cardioativos. A absorção pelo organismo é cumulativa de modo que a intoxicação é mais freqüentemente crônica do que aguda, provocando mal-estar, náuseas, convulsões e morte por parada cardíaca. Na região a espécie é utilizada na forma de banho para o tratamento de problemas na pele.

- Jatropha spp. (pinhão-branco, pinhãoroxo). O látex de Jatropha sp. é cáustico e de ação irritante sobre pele e mucosas, o mesmo ocorrendo com pêlos e espinhos no caso de algumas espécies. A semente possui também um complexo resinoso, alcalóides, glicosídios e toxalbuminas. O complexo resino-lipóide é considerado como responsável pela dermatite produzida pela planta. Os glicosídios encontrados na casca da semente têm ação depressora sobre os sistemas respiratório e cardiovascular, além de ação estimulante sobre a musculatura gastrintestinal, esta seria uma das responsáveis por seus efeitos purgativos (Schvartsman, 1979). Os erveiros da região, indicam a espécie Jatropha gossypifolia para o preparo de banhos ritualísticos.

- Solanum spp. Muitas plantas da família Solanaceae pertencentes a este gênero são portadoras de um alcalóide, a solanina que embora em sua forma natural não sejam bem absorvidos, produzem por hidrolise subseqüente à sua ingestão, uma outra substância, esta absorvível e responsável pelos fenômenos de intoxicação. Os sintomas se traduzem por embotamento dos sentidos, estupor e,

Rodriguésia 52(80): 47-59. 2001. dependendo da dose, morte por parada respiratória (Matos, 1989). No presente trabalho, é relatada a utilização de $S$. cernuum para o tratamento de problemas renais, $S$. paniculatum como depurativo e Solanum sp., na forma de banho para o tratamento de queda de cabelo e caspa.

- Symphytum officinale (confrei). Este gênero, junto com o gênero Heliotropium é, segundo Matos (1989), considerado perigoso pela presença de certos alcalóides considerados cancerígenos. Estas substâncias são responsáveis por uma manifestação tóxica conhecida como doença veno-oclusiva que se localiza preferencialmente no fígado, resultando em cirrose hepática tardia e câncer causado por seu efeito cumulativo tardio, ou seja, de ocorrência após longo tempo de ingestão da dose tóxica. Na região a espécie é utilizada na forma de banho para o tratamento de problemas de pele e feridas.

Bortoletto et al. (1998) ressaltam, em trabalho sobre a participação de plantas nas intoxicações humanas no período de 1993 a 1996, que dos 13 agentes tóxicos considerados pelo Sistema Nacional de Informações TóxicoFarmacológicas (SINITOX), as plantas ocuparam o nono lugar com $2,7 \%$ do total de casos. Destacam ainda, que no grupo etário de crianças menores de 10 anos as intoxicações por plantas ocupam o quarto lugar dentre os demais agentes tóxicos. Em relação a casos letais, as plantas superaram os óbitos causados por medicamentos. Estes autores destacam a família Euphorbiaceae, contribuindo com o maior número de casos de intoxicação, além de Araceae e Solanaceae. Dentre as espécies utilizadas como medicinais na região, sete pertencem a estas famílias. Enquanto que dentre as espécies citadas como venenosas por Schvartsman (1979), apenas Asclepias curassavica, Jatropha gossypifolia, Lantana camara e Melia azedarach foram citadas pelos erveiros da área de estudo. 


\section{AGRADECIMENTOS}

Ao Sr. Jorge Borges da Paixão (in memorian) e Sra. Maria Aparecida por dividirem seus conhecimentos, sem os quais este trabalho não seria realizado. Aos botânicos Lana da Silva Sylvestre, Genise Vieira Freire e R. Harley, pela colaboração na identificação do material botânico. À Inês Machline Silva pelas valiosas sugestões.

\section{REFERÊNCIAS BIBLIOGRÁFICAS}

Albuquerque, U. P. \& Chiapetta, A. de A. 1994. O uso de plantas e a concepção de doença e cura nos cultos afro-brasileiros, Recife, Brasil. Ci. \& Tróp., 22(2): 197210.

Albuquerque, U. P. \& Chiapetta, A. de A. 1995. Formas de uso de espécies vegetais dos cultos afro-brasileiros em Recife - PE, Brasil. Biologica brasilica, 6(1/2): 111-120.

Albuquerque, U. P. \& Chiapetta, A. de A. Contribuição etnobotânica para o universo ritual dos cultos afro-brasileiros. In: Lima, T. (org.) 1996. Sincretismo Religioso: O Ritual Afro. Recife, Massaneana; p.188-197. IV Congresso Afro-brasileiro.

Alexiades, M.N. 1996. Selected Guidelines for Ethnobotanical Research: a Field Manual. New York Botanical Garden, New York. 306p.

Almeida, E. R. 1993. Plantas Medicinais Brasileiras. São Paulo, Ed. Hemus. 341p.

Amorozo, M. C. de M. A abordagem etnobotânica na pesquisa de plantas medicinais. In: Di Stasi, L.C. (organizador). $1996 . \quad$ Plantas Medicinais: arte e ciência. Um guia de estudo multidisciplinar. 1a. ed. São Paulo, Ed. Unesp. p. 47-68. \& Gély, A. 1988. Uso de plantas medicinais por caboclos do baixo Amazonas, Bacarena, PA, Brasil. Bol. Mus. Para. Emilio Goeldi, Ser. Bot. Belém, 4(1): 47-131.
Bortoletto M. E.; Bochner, R. \& Lourencini, R. 1998. A participação das plantas nas intoxicações humanas. Brasil, 1993 a 1996. XLIX Congresso Nacional de Botânica. Salvador, BA.

Camargo, M. T. L. de A. 1985. Medicina Popular. 1a ed., São Paulo; ALMED.130p. 1988. Plantas medicinais e de rituais afro-brasileiros $I .1$ ed., São Paulo; ALMED. 97 p.

Debuigne, G. 1974. Larousse des plantes qui guérissent. Librairie Larousse, Paris. $254 \mathrm{p}$.

Martin, G.J. 1995. Ethnobotany - A method manual. Chapman \& Hall, New York. 268p.

Matos, F. J. A. 1989. Plantas Medicinais; guia de seleção e emprego de plantas usadas em fitoterapia no Nordeste do Brasil. vol. 1. Fortaleza, IOCE. 164 p.

Mori, S. A. 1989. Eastern Extra-Amazonian Brasil. In: Campbell, D. \& Hammond, D. Floristic Inventory of Tropical Countries. New York Botanical Garden, New York, NY. USA. p. 426-454.

Peixoto, A. L.; Rosa, M. M. T. da; Barbosa, M. R. V. \& Rodrigues, H. C. 1995. Composição florística do entorno da Represa de Ribeirão das Lages, Rio de Janeiro, Brazil. Rev. Univ. Rural, Sér. Ciênc. da Vida, 17(1): 51-74.

Reis, M.S. dos. Manejo sustentado de plantas medicinais em ecossistemas tropicais. In: Di Stasi, L. C. (organizador) 1996. Plantas Medicinais: arte e ciência. Um guia de estudo multidisciplinar. 1a. ed. São Paulo, Ed. Unesp. p. 199-215.

Ribeiro, R. A. \& Gomes, C. 1986. Triagem farmacológica de plantas com atividades anti-hipertensiva e diurética, XI Simpósio de Plantas Medicinais do Brasil. Rio de Janeiro, RJ.

Rizzini, C. T. 1976. Tratado de Fitogeografia do Brasil. Vol. 1. Ed. Hucitec, Rio de Janeiro, RJ, Brasil. 327 p.

Rosa, M. M. T. da, Silva, I. M. \& Chagas, K. 
C. 1991. Plantas utilizadas como medicinais no município de Seropédica, Rio de Janeiro, Brasil. XLII Congresso Nacional de Botânica, Goiânia, GO.

Roveratti, D. S. 1998. Análise comparativa sobre espécies medicinais utilizadas por comunidades urbanas de diferentes regiões do território brasileiro. XLIX Congresso Nacional de Botânica, Salvador, BA.

Savastano, M. A. P. \& Di Stasi, L. C. Folclore: conceitos e metodologia. In: Di Stasi, L. C. (organizador) 1996. Plantas Medicinais: arte e ciência. Um guia de estudo multidisciplinar. 1a. ed. São Paulo, Ed. Unesp. p. 37-46.

Schvartsman, S. 1979. Plantas Venenosas. São Paulo, Ed. Sarvier. 176 p.

Sheldon, J.W.; Balick, M.J. \& Laird, S.A. 1997. Medicinal Plants: can utilization and conservation coexist?. New York Botanica Garden, New York. 104p.

Silva, I. M.; Rosa, M. M. T. da \& Silva-Neto, S. J. 1992. Plantas com potencial medicinal, tintorial e condimentar encontradas na Represa de Ribeirão das Lages. XLIII Congresso Nacional de Botânica. Aracajú, SE.

Simões, C. M. O. 1989. Plantas da medicina popular do Rio Grande do Sul 3ed Porto Alegre: Editora da Universidade/ UFRGS $174 \mathrm{p}$.

Somavilla, N. \& Canto-Dorow, T. S. do, 1996. Levantamento das plantas medicinais utilizadas em bairros de Santa Maria, RS, Brasil. Ciência e Natura, 18: 31-148.

Sydenstricker, L. 1993. Guia sócioeconômico dos municípios do Estado do Rio de Janeio. Vol 2. Gráfica JB, Rio de Janeiro. P. 159-162.

Verger, P. F. 1995. Ewé: O uso das plantas na sociedade iorubá. 1 ed. São Paulo: Companhia das Letras. $762 \mathrm{p}$ 
